\title{
Preventing Diabetic Complications by Dietary Agents
}

\author{
Noor Fatima, Hira Jawed, Shahrukh Momin and Rahman M Hafizur* \\ International Center for Chemical and Biological Sciences, University of Karachi, Pakistan
}

Submission: March 12, 2019; Published: May 07, 2019

*Corresponding author: Rahman M Hafizur, Dr. Panjwani Center for Molecular Medicine and Drug Research, International Center for Chemical and Biological Sciences, University of Karachi, Karachi-75270, Pakistan

\begin{abstract}
Diet is vital for survival whereas balanced diet and nutrition are crucial for healthy living. Dietary agents, such as fruits, vegetables, and spices; are consumed in daily meals. Dietary agents are available and affordable all over the world which makes them suitable candidate for preventing diabetic complications. The scientific validation for their health-related benefits and anti-diabetic potential; mainly, is a big trumpet for their usefulness in indigenous cultures all around the world. In order to successfully manage diabetes, medicinal and nutritional interventions are supposed to go hands in hands. At present, medicines are available for diabetes managements; but diabetic complications are completely ignored. Therefore, dietary agents should be given more emphasis for the prevention and/or management of diabetes related complication. Dietary agents are rich in nutritional values and daily consumption makes them more palatable. In this regard, dietary agents may play an important role for preventing diabetic complication.
\end{abstract}

Keywords: Dietary agents; Glycation; Diabetic complications; HbA1c; Antiglycation; Advanced glycation end products; Diabetes; Glucophages; Insulin secretagogues; Glycation; Lipid peroxidation; Nitro oxidation; Free radical formations; DNA damage

Abbreviations: HbA1c: Glycated Hemoglobin; AG: Aminoguanidine; AGEs: Advanced Glycation End-Products; CML: N-Carboxymethyl Lysine; CEL: N-Carboxyethyl Lysine

\section{Introduction}

Diabetes has been emerged as an epidemic of modern era due to changes in life style, ageing, and nutritional imbalances [1]. Modernization has been one of the sources in shifting life paradigm and increased rate of diabetes. Once a person is diabetic, it is always diabetic. Western countries have more health emphasis and there are routine checkups, so early diagnosis for diabetes is possible. The healthy life style and increased muscle to fat mass ratio is another factor for development of diabetes in later ages. The scenario is totally reversed in East, especially Asian countries, where healthcare is given less importance. Asian people have low muscle to fat mass ratio, and develop diabetes in their early ages, like 20 years of age. The changes in the body due to development of diabetes lead to diabetic complications. The medicines that are available in the market are majorly glucophages and insulin secretagogues. Glucophages have side effects as leading to hypoglycemia and related deaths [2]. On the other hand, insulin secretagogues over burden $\beta$-cells to secrete insulin despite their low functionality, resulting in complete failure of $\beta$-cells. This leads to absolute shift from medicines to exogenous insulin demand. The marketed drugs formulated for diabetes are mainly single molecules that have single targets. While in diabetes there are many pathways that lead to its complications such as; glycation, lipid peroxidation, nitro oxidation, free radical formations, DNA damage, etc [3].

Thus, in this scenario, a single molecule may or may not be helpful in targeting multiple pathways. In general, type 1 diabetic patients develop diabetic complications after 10 years of diagnosis, while in type 2 diabetic patients, complications can be evolved at any time point in uncontrolled and late diagnosed diabetic subjects. Asian subjects are commonly late diagnosed for diabetes; therefore, when a person is initially diagnosed, it is already delayed diabetes and most of the complications are present. For diabetic complication and glycation, aminoguanidine, the first AGEs inhibitor has been studied extensively and has shown promising results both in in vitro and in vivo.

It prevents AGEs formation by preventing the formation of cross linking, its potential to trap the reactive carbonyls that are involved in AGEs conversion and ability to prevent the formation of free radicals, lipid peroxidation and apoptosis that is induced by oxidative stress. But it was retreated from phase III trials due to its various adverse effects. Scientists are formulating many 
drug candidate molecules for diabetes related complications, but it will take time for a successful drug to be marketed. Since no drug is available in the markets for the treatment of diabetic complications; therefore, dietary agents could successfully fill this gap [4].

The hallmark of diabetic complications is glycation, a physiological phenomenon occurs in the organisms due to nonenzymatic glycation. It becomes pathologic in many diseases including atherosclerosis, Alzheimer's disease, cataract, ageing, rheumatoid arthritis, impaired wound healing, diabetic nephropathy, diabetic neuropathy, etc. These pathological conditions have increased rate of glycation, among them diabetic subjects are more susceptible due to hyperglycemia. In diabetes, glycation occurs 14 times more than healthy subjects. Glycation is the process chemical of rearrangements of protein and carbohydrate moiety. Due to persistent hyperglycemia, more carbohydrates (mainly glucose and fructose molecules) are present, thus there are more possibilities for occurrence of non-enzymatic glycation. These glycated adducts change the structural features of proteins thus altering the protein functions. Proteins having low turnover rate are causing long term damages. These proteins include collagen, eye lens crystalline, elastin, enamel and dentine [5].

Dietary agents, such as fruits, vegetables, and spices are excellent components of the diet in diabetic patients. This is for their high nutritional values, rich antioxidant and for their palatability which increase patient's compliance. In order to successfully manage diabetes, medicinal and nutritional interventions are supposed to go hands in hands. People consume many dietary agents (leaves, fruits, vegetables, seeds, etc) in their routine as cooked or uncooked foodstuff. Many dietary agents are known for the anti-diabetic potentials. In this regard, DAs are suitable as alternative sources for diabetic complication preventive measures. In this mini review, we are sharing our experiences (Figure 1) and discuss the potential role of some dietary agents for preventing diabetic complications.

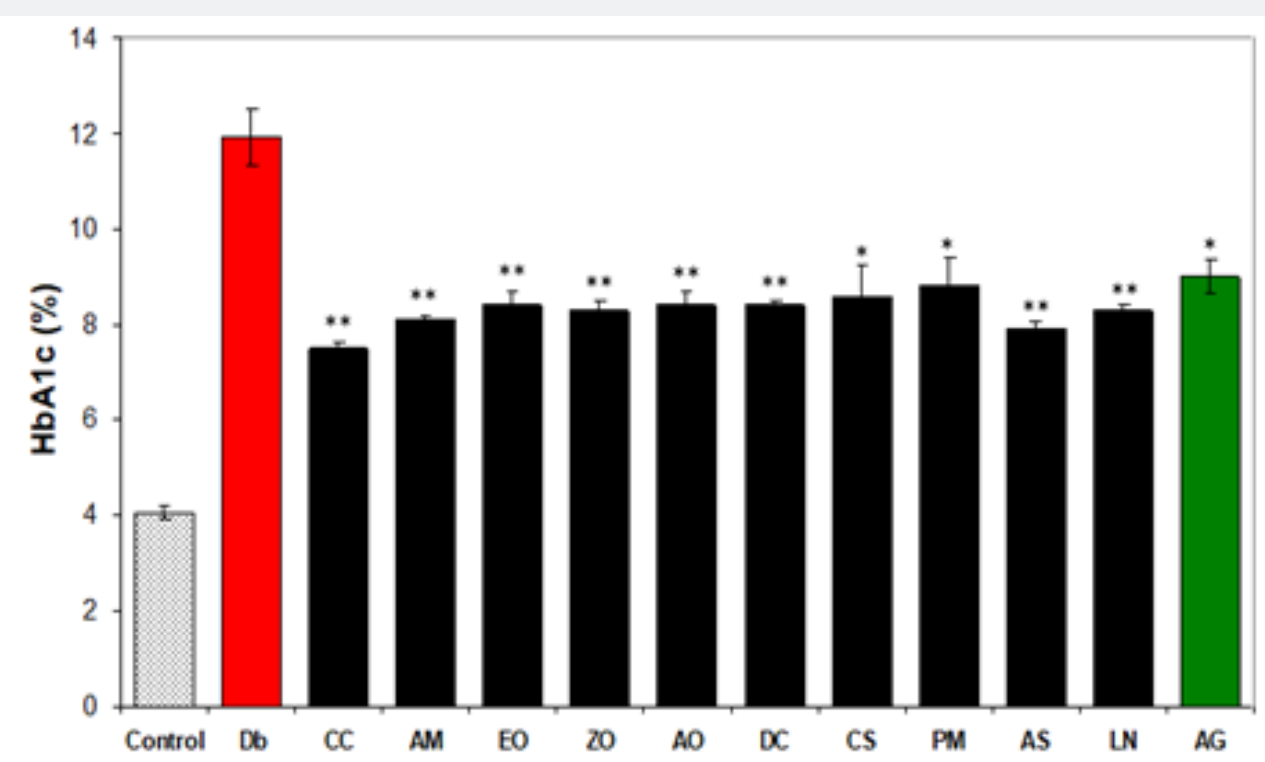

Figure 1: Effect of 10 dietary agents on $\mathrm{HbA} 1 \mathrm{c}$ in the diabetic rats. Values are mean \pm S.E.M. for 6-8 rats per group. Control, non-diabetic control; Db, untreated diabetic rats; CC, diabetic rats treated with Cinnamomum cassia extract $500 \mathrm{mg} / \mathrm{kg}$; AM, diabetic rats treated with Aegle marmelos extract $500 \mathrm{mg} / \mathrm{kg}$; EO, diabetic rats treated with Emblica officinalis extract $500 \mathrm{mg} / \mathrm{kg} ; \mathrm{ZO}$, diabetic rats treated with Zingiber officinalis extract $500 \mathrm{mg} / \mathrm{kg}$; AO, diabetic rats treated with Asparagus officinalis extract $500 \mathrm{mg} / \mathrm{kg}$; DC, diabetic rats treated with Daucus carota extract $500 \mathrm{mg} / \mathrm{kg}$; CS, diabetic rats treated with Citrus sinensis (L.) Osbeck extract $500 \mathrm{mg} / \mathrm{kg}$; PM, diabetic rats treated with Pyrus malus extract $500 \mathrm{mg} / \mathrm{kg}$; AS, diabetic rats treated with Allium sativum extract $500 \mathrm{mg} / \mathrm{kg}$; LS, diabetic rats treated with Laurus nobilis extract $500 \mathrm{mg} / \mathrm{kg}$, respectively; AG, Aminoguanidine, as positive control. ${ }^{*} \mathrm{P}<0.01,{ }^{* *} \mathrm{P}<0.001$, vs. Db group.

\section{Cinnamomum cassia}

Cinnamomum cassia is a spice consume in culinary purposes. Indigenous knowledge regarding C. cassia is rich in treatment of many ailments including diabetes; however, there are differences of opinion based on scientific studies [6-9]. Some studies report inhibition of early and advanced glycation products by $C$. cassia while other studies contradict them. We have found water extract of $C$. cassia exhibits antiglycation activity by lowering HbA1c [10], AGEs, and CML in diabetic rats.

\section{Aegle marmelos}

Different parts of Aegle marmelos such as pulp, leaves, flowers, seeds, stem and roots are being used as ethnomedicine to overcome many infections and diseases including diabetes $[11,12]$. However, there is little known about antiglycation activity of $A$. marmelos [13]. We have reported A. marmelos decreases HbA1c and AGEs in plasma and prevented AGEs and CML deposition in kidneys of diabetic rats [14]. 


\section{Current Research in Diabetes \& Obesity Journal}

\section{Asparagus officinalis}

Asparagus officinalis is rich in minerals, vitamins, and photonutrients. We have reported antidiabetic activity of $A$. officinalis [15]; however, the antiglycation activity of $A$. officinalis has not been reported. We have found antiglycation activity of $A$. officinalis in vitro and $\mathrm{HbA} 1 \mathrm{c}$ lowering potential in diabetic rats.

\section{Zingiber officinale}

Zingiber officinale is rich in vitamins and minerals. The animal model of diabetes has shown the antidiabetic activity of $Z$. officinale $[16,17]$. The antiglycation activity of $Z$. officinale through in vitro as well as in vivo using diabetic rats has been reported $[18,19]$. We have also found in vitro antiglycation activity of $Z$. officinale.

\section{Emblica officinalis}

The Emblica officinalis fruit contains amino acids, minerals, and is rich in vitamin C [20]. We have reported that E. officinalis significantly improve total antioxidant status in diabetic rats [21]. It also exhibits the antiglycation activity in in vitro BSAglucose glycation as well as decrease in vivo HbA1c levels and serum advanced glycation end products levels, as well as its deposition in kidneys (unpublished data).

\section{Daucus carota}

Daucus carota root is commonly used food all around the world. However very few scientific literatures are available for its anti-diabetic potential [22,23]. In our experience, we have found that $D$. carota has potential of antiglycation activity in vivo.

\section{Citrus sinensis (L.) Osbeck}

Citrus sinensis (L.) Osbeck fruit has beneficial health effects as it is rich in vitamin $\mathrm{C}$; however, scientific studies regarding anti diabetic activity is much less $[24,25]$. We have found that $C$. sinensis has in vivo antiglycation activity.

\section{Pyrus malus}

Pyrus malus fruit is universally known as healthy treat in health and disease state; however, regarding scientific literature for its anti-diabetic effects, very little information is available [26]. We have found that P. malus has antiglycation activity in vivo.

\section{Allium sativum}

Allium sativum cloves are used in every kitchen all around the world and the anti-diabetic activity of $A$. sativum is well reported [27-39]. We have found antiglycation effects of A. sativum cloves in in vivo.

\section{Laurus nobilis}

Laurus nobilis leaves are commonly used in culinary purposes as spice. The anti-diabetic potential $[40,41]$ and in vitro antiglycation potential of L. nobilis is reported [42]. In our studies, we have also found that L. nobilis has in vivo antiglycation potential.

\section{Discussion}

In uncontrolled diabetes, a number of proteins including albumin, $\alpha$-crystallin, hemoglobin, etc are glycated rapidly. The HbA1c, one of the major glycated products in diabetes, is the most useful indicator for glycemic status [43].

In diabetes, the high blood glucose causes the accelerated formation of AGEs that circulate in blood as well as accumulate in certain tissues, thus it is one of the major causes of diabetic complications $[44,45]$. So, the status of AGEs in blood as well as in tissues is an important predictor of diabetic complications. Therefore, the control of blood glucose in diabetes is needed to prevent the formation of AGEs as well as diabetic complications. Along with the circulating AGEs, the AGEs are also accumulated in the various organs especially kidney which is the major target of AGEs-mediated damage as a consequence of diabetes. With the duration and severity of diabetes, the AGEs accumulation increases in Bowman's capsule, glomerular basement membrane, glomerular mesangium and tubular basement membrane $[46,47]$. As AGEs are adducts of carbohydrates and proteins, therefore any strategy to block or inhibit adduct formation would play significant role in preservation of functional structure of proteins.

Dietary agents are believed to have multiple targets due to presence of hundreds of different molecules and natural compounds. Rutin is the example of molecule having multiple modes of actions in different disease models. It is one of a pigment presents in many vegetables and fruits. Therefore, these dietary agents have multiple targets that play their role in preventing multiple disorders.

These dietary agents are the mixture of molecules that could have multiple binding sites and modes of action. Diabetic complications arise from multiple scenarios like; glycation, lipid peroxidation, nitro oxidation, free radicals' formations, DNA damage, etc, therefore managing these complications with such dietary agents have edge over medication. Dietary agents are the mixture of multiple molecules that have the possibility to interact with multiple sites in the living system. The formation of glycation adducts start with binding of aldehyde group of sugar with amino moiety of proteins. Dietary agents are rich in flavonoids, reducing sugars, and other reducing compounds, have possibilities to break this cascade by interacting with these aldehyde group of sugar or/and amino moiety of proteins. Another possibility of formation of glycation adducts is by linking of methyl or ethyl moieties with lysine or arginine residues of proteins eg: CML or CEL. We have found that these have the ability to reduce AGEs and CML deposition in the kidneys of diabetic animals. It postulates that in the presence suitable/correct of dietary agents in the body, the formation of 


\section{Current Research in Diabetes \& Obesity Journal}

glycation adducts is halted thus, structural modification proteins is prevented.

\section{Conclusion}

The consumption of suitable dietary agents is linked with delaying in diabetic complication and reducing the direct and indirect cost of medication per diabetic subjects. It would be beneficial and have low cost in the era where little to no drug is available in market for breaking and/or preventing glycation.

\section{Acknowledgments}

This work was supported by HEC grant No. 20-8544 to M. Hafizur Rahman from the Higher Education Commission, Pakistan.

\section{References}

1. Jaacks LM, Vandevijvere S, Pan A, McGowan CJ, Wallace C, et al. (2019) The obesity transition: stages of the global epidemic. Lancet Diabetes Endocrinol 7(3): 231-240.

2. Jacob T, Garrick R, Goldberg MD (2018) Recurrent lactic acidosis and hypoglycemia with inadvertent metformin use: a case of look-alike pills. Endocrinol Diabetes Metab Case Rep.

3. Ayepola OR, Brooks NL, Oguntibeju OO (2014) Oxidative stress and diabetic complications: the role of antioxidant vitamins and flavonoids, in Antioxidant-Antidiabetic Agents and Human Health. Intech Open p. 26-58.

4. Freedman BI, Wuerth JP, Cartwright K, Bain RP, Dippe S, et al. (1999) Design and baseline characteristics for the aminoguanidine Clinical Trial in Overt Type 2 Diabetic Nephropathy (ACTION II). Con Clin Trials 20(5): 493-510.

5. https://www.quora.com/What-are-some-examples-of-extremelylong-lived-proteins.

6. Akilen R, Tsiami A, Devendra D, Robinson N (2010) Glycated haemoglobin and blood pressure-lowering effect of cinnamon in multi-ethnic type 2 diabetic patients in the UK: a randomized, placebocontrolled, double-blind clinical trial. Diabetic Med 27(10): 11591167.

7. Blevins SM, Leyva MJ, Brown J, Wright J, Scofield RH, et al. (2007) Effect of cinnamon on glucose and lipid levels in non-insulin-dependent type 2 diabetes. Diabetes Care 30(9): 2236-2237.

8. Crawford P (2009) Effectiveness of cinnamon for lowering hemoglobin A1c in patients with type 2 diabetes: a randomized, controlled trial. J Am Board Fam Med 22(5): 507-512.

9. Mang B, Wolters M, Schmitt B, Kelb K, Lichtinghagen R, et al. (2006) Effects of a cinnamon extract on plasma glucose, HbA1c, and serum lipids in diabetes mellitus type 2. Eur J Clin Invest 36(5): 340-344.

10. Fatima N, Khaleeq A, Momin S, Waraich RS, Khaliq S (2017) Modulation of pancreatic $\beta$-cells and antioxidant status by cinnamon in type 2 diabetic rats. J Cytol Histol 8(4): 477.

11. Maity P, Hansda D, Bandyopadhyay U, Mishra DK (2009) Biological activities of crude extracts and chemical constituents of Bael, Aegle marmelos (L.) Indian J Exp Biol 47(11): 849-860.

12. Patel PK, Sahu J, Sahu L, Narendra K, Prajapati (2012) Aegle marmelos: a review on its medicinal properties. Int J Pharma Phytopharmacol Res 1(5): 332-341.

13. Kamalakkanan N, Rajadurai M, Prince PSM (2003) Effect of Aegle marmelos fruits on normal and streptozotocin-diabetic Wistar rats. Med Food 6(2): 93-98.
14. Hafizur RM, Momin S, Fatima N (2017) Prevention of advanced glycation end-products formation in diabetic rats through beta-cell modulation by Aegle marmelos. BMC Complement Altern Med 17(1): 227.

15. Hafizur RM, Kabir N, Chishti S (2012) Asparagus officinalis extract controls blood glucose by improving insulin secretion and $\beta$-cell function in streptozotocin-induced type 2 diabetic rats. Br J Nutr 108(9): 1586-1595.

16. Akhani SP, Vishwakarma SL, Goyal RK (2004) Anti-diabetic activity of Zingiber officinale in streptozotocin-induced type I diabetic rats. J Pharm Pharmacol 56(1): 101-105.

17.Al-Amin ZM, Thomson M, Al-Qattan KK, Peltonen-Shalaby R, Ali $M$ (2006) Anti-diabetic and hypolipidaemic properties of ginger (Zingiber officinale) in streptozotocin-induced diabetic rats. Br J Nutr 96(4): 660-666.

18. Saraswat M, Reddy PY, Muthenna P, Reddy GB (2008) Prevention of non-enzymic glycation of proteins by dietary agents: prospects for alleviating diabetic complications. Br J Nutr 101(11): 1714-1721.

19. Saraswat M, Suryanarayana P, Reddy PY, Patil MA, Balakrishna N, et al. (2010) Antiglycating potential of Zingiber officinalis and delay of diabetic cataract in rats. Mol Vis 16: 1525-1537.

20. Mirunalini S, Krishnaveni M (2010) Therapeutic potential of Phyllanthus emblica (amla): the ayurvedic wonder. J Basic Clin Physiol Pharmacol 21(1): 93-105.

21. Fatima N, Hafizur RM, Hameed A, Ahmed S, Nisar M, et al. (2017) Ellagic acid in Emblica officinalis exerts anti-diabetic activity through the action on $\beta$-cells of pancreas. Eur J Nutr 56(2): 591-601.

22. El-Houri RB, Kotowska D, Christensen KB, Bhattacharya S, Oksbjerg N, et al. (2015) Polyacetylenes from carrots (Daucus carota) improve glucose uptake in vitro in adipocytes and myotubes. Food Funct 6(7): 2135-2144.

23. Esatbeyoglu T, Rodríguez-Werner $\mathrm{M}$, Schlösser A, Liehr $\mathrm{M}$, Ipharraguerre I, et al. (2016) Fractionation of plant bioactives from black carrots (Daucus carota subspecies sativus varietas atrorubens alef.) by adsorptive membrane chromatography and analysis of their potential anti-diabetic activity. J Agric Food Chem 64(29): 5901-5908.

24. Mallick N, Khan RA (2015) Effect of Citrus paradisi and Citrus sinensis on glycemic control in rats. Afr J Pharm Pharmacol 9(3): 60-64.

25. Parmar HS, Kar A (2008) Medicinal values of fruit peels from Citrus sinensis, Punica granatum, and Musa paradisiaca with respect to alterations in tissue lipid peroxidation and serum concentration of glucose, insulin, and thyroid hormones. J Med Food 11(2): 376-381.

26. Munir M, Qureshi R (2018) Antidiabetic plants of Pakistan, in Plant and Human Health. Springer 1: 463-545.

27. Ayodhya S, Kusum S, Anjali S (2010) Hypoglycaemic activity of different extracts of various herbal plants. Int J Res Ayurveda Pharm (IJRAP) 1(1): 212-224.

28. Bokaeian M, Nakhaee A, Moodi B, Farhangi A, Akbarzadeh A (2010) Effects of garlic extract treatment in normal and streptozotocin diabetic rats infected with Candida albicans. Ind J Clin Biochem 25(2): 182-187.

29. Chauhan A, Sharma PK, Srivastava P, Kumar N (2010) Plants having potential antidiabetic activity: a review. Pharm Lett 2(3): 369-387.

30. Dineshkumar B, Analava M, Manjunatha M (2010) Antidiabetic and hypolipidaemic effects of few common plants extract in type 2 diabetic patients at Bengal. Int J Diabetes and Metabolism 18(2): 59-65.

31. Eidi A, Eidi M, Esmaeili E (2006) Antidiabetic effect of garlic (Allium sativum L.) in normal and streptozotocin-induced diabetic rats. Phytomedicine 13(9-10): 624-629. 


\section{Current Research in Diabetes \& Obesity Journal}

32. Islam MS, Choi H (2008) Dietary red chilli (Capsicum frutescens L.) is insulinotropic rather than hypoglycemic in type 2 diabetes model of rats. Phytother Res 22(8): 1025-1029.

33. Khayatnouri M, Bahari K, Safarmashaei S (2011) Study of the effect of gliclazide and garlic extract on blood sugar level in STZ-induced diabetic male mice. Adv Environ Biol 1751-1756.

34. Liu CT, Wong PL, Lii CK, Hse H, Sheen LY (2006) Antidiabetic effect of garlic oil but not diallyl disulfide in rats with streptozotocin-induced diabetes. Food Chem Toxicol 44(8): 1377-1384.

35. Mahesar H, Bhutto MA, Khand AA, Narejo NT (2010) Garlic used as an alternative medicine to control diabetic mellitus in alloxan-induced male rabbits. Pak J Physiol 6(1): 39-41.

36. Mandlik RV, Desai SK, Naik SR, Sharma G, Kohli RK (2008) Antidiabetic activity of a polyherbal formulation (DRF/AY/5001). Ind J Exp Biol 46(8): 599-606.

37. Modak M, Dixit P, Londhe J, Ghaskadbi S, Devasagayam TP (2007) Indian herbs and herbal drugs used for the treatment of diabetes. J Clin Biochem Nutr 40(3): 163-173.

38. Mustafa SS, Eid NI, Jafri SA, El-Latif HA, Ahmed HM (2007) Insulinotropic effect of aqueous ginger extract and aqueous garlic extract on the isolated perfused pancreas of streptozotocin induced diabetic rats. Pak J Zool 39(5): 279.

39. Thomson M, Al-Amin ZM, Al-Qattan KK, Shaban LH, Ali M (2007) Antidiabetic and hypolipidaemic properties of garlic (Allium sativum) in streptozotocin-induced diabetic rats. Int J Diabetes \& Metabolism 15: 108-115.
40. Aljamal A (2011) Effect bay leaves on the patients with diabetes mellitus. Res J Med Plants 5(4): 471-476.

41. Basak SS, Candan F (2013) Effect of Laurus nobilis L. essential oil and its main components on $\alpha$-glucosidase and reactive oxygen species scavenging activity. Iran J Pharm Res 12(2): 367.

42. Dearlove RP, Greenspan P, Hartle DK, Swanson RB, Hargrove JL (2008) Inhibition of protein glycation by extracts of culinary herbs and spices. J Med Food 11(2): 275-281.

43. Uchimura T, Nakano K, Hashiguchi T, Iwamoto H, Miura K, et al. (2001) Elevation of $\mathrm{N}$-(carboxymethyl) valine residue in hemoglobin of diabetic patients: its role in the development of diabetic nephropathy. Diabetes Care 24(5): 891-896.

44. Aso Y, Inukai T, Tayama K, Takemura Y (2000) Serum concentrations of advanced glycation endproducts are associated with the development of atherosclerosis as well as diabetic microangiopathy in patients with type 2 diabetes. Acta Diabetol 37(2): 87-92.

45. Berg TJ, Bangstad HJ, Torjesen PA, Osterby R, Bucala R, et al. (1997) Advanced glycation end products in serum predict changes in the kidney morphology of patients with insulin-dependent diabetes mellitus. Metabolism 46(6): 661-665.

46. Bendayan M (1998) Immunocytochemical detection of advanced glycated end products in rat renal tissue as a function of age and diabetes. Kidney International 54(2): 438-447.

47. Verbeke P, Perichon M, Borot-Laloi C, Schaeverbeke J, Bakala H (1997) Accumulation of advanced glycation endproducts in the rat nephron: link with circulating AGEs during aging. J Histochem Cytochem 45(8): 1059-1068.

\begin{tabular}{l} 
Your next submission with Juniper Publishers \\
will reach you the below assets \\
- Quality Editorial service \\
- Swift Peer Review \\
- Reprints availability \\
- E-prints Service \\
- Manuscript Podcast for convenient understanding \\
- Global attainment for your research \\
- Manuscript accessibility in different formats \\
( Pdf, E-pub, Full Text, Audio) \\
- Unceasing customer service \\
Track the below URL for one-step submission \\
https://juniperpublishers.com/online-submission.php \\
\hline
\end{tabular}

